\title{
Currículo de Ciências: a alquimia das disciplinas escolares e a produção da autonomia docente
}

\author{
Science curriculum: alchemy of school subjects and production of \\ teaching autonomy
}

\section{Currículo de ciencias: alquimia de las asignaturas escolares y producción de autonomía docente}

\author{
Marcia Serra Ferreira' \\ Universidade Federal do Rio de Janeiro, Programa de Pós-graduação em Educação, \\ Professora associada. \\ https://orcid.org/0000-0002-2034-5992 \\ Maria Margarida Gomes ${ }^{2}$ \\ Universidade Federal do Rio de Janeiro, Programa de Pós-graduação em Educação, \\ Professora associada. \\ https://orcid.org/0000-0002-8609-3898
}

Resumo: 0 trabalho investiga a produção do currículo da disciplina escolar Ciências em uma escola municipal que recebe licenciandos de Ciências Biológicas da Universidade Federal do Rio de Janeiro para as atividades de estágio supervisionado. Focaliza, especialmente, o modo como licenciandos se constituem professores em meio à experiência de produzir esse currículo. Para realizar essa tarefa, associamos as nossas observações durante o estágio supervisionado com a realização de uma roda de conversa com os licenciandos que atuaram, durante o ano de 2019, em uma instituição escolar específica. No diálogo com Michel Foucault e Thomas Popkewitz, investimos na ideia de que os processos alquímicos que transformam as ciências de referência em conhecimentos escolares também produzem, simultaneamente, os professores bons e adequados lassim como os não tão bons e pouco adequados) para ensiná-los. Na análise, percebemos o quanto a noção de autonomia docente foi assumida como central no processo formativo, em um movimento que articulou a construção curricular em torno dos conhecimentos, materiais didáticos e avaliações. Aspectos como o uso de atividades práticas e a criatividade foram enunciados como participando da constituição desse bom professor, capaz de ressignificar a escola pública e seus sujeitos e de subverter os modos de regulação e controle impostos pelas políticas centralizadas. No processo formativo, além dos conhecimentos científicos, os enunciados de cunho pedagógico foram assumidos como bastante significativos na

Doutora em Educação pela Universidade Federal do Rio de Janeiro; Mestre em Educação pela Pontifícia Universidade Católica do Rio de Janeiro.

2 Doutora em Educação pela Universidade Federal Fluminense; Mestre em Currículo e Ensino pela Universidade do Kansas. 
constituição de um profissional capaz de fugir à norma, participando da construção do currículo de forma ativa, criativa e autônoma.

Palavras-chave: Currículo. Disciplina escolar. Ciências. Formação de professores. Alquimia das disciplinas escolares. Autonomia docente.

Abstract: In this article, the production of Science school curriculum in a municipal school of Rio de Janeiro, Brazil, is investigated. That school receives undergraduate's students of Biological Sciences from the Federal University of Rio de Janeiro for teachers' training supervised internship activities. It focuses on the way undergraduate students become teachers through the experience of producing this curriculum. So we associated our observations to a conversation with the undergraduates who worked in their supervised internship, during 2019, in a specific school institution. Supported by Michel Foucault and Thomas Popkewitz, we argue that the alchemical processes that transform the sciences into school knowledge also produce, at the same time, good and suitable teachers las well as not so good and unsuitable). In the analysis, we realized how the teacher autonomy has assumed to be central to the teachers' training process which has articulated the curriculum construction around knowledge, teaching materials and assessments. Aspects such as the use of practical activities and creativity were enunciated as participating in the constitution of this good teacher, capable of understanding public school. Besides that, he or she is also suitable to subvert the modes of regulation and control imposed by centralized policies. In the formative process, in addition to scientific knowledge, the pedagogical statements were assumed to be quite significant in the constitution of a professional capable of escaping the norm, participating in the construction of the curriculum in an active, creative and autonomous way.

Keywords: Curriculum. Science as a school subject. Initial teacher training. Alchemy of school subjects. Teaching autonomy.

Resumen: El trabajo investiga la producción del curriculum de la disciplina Ciencias en una escuela municipal que recibe graduados de Ciencias Biológicas de la Universidad Federal de Río de Janeiro para actividades supervisadas de pasantías. Se centra en como los estudiantes de pregrado se convierten en maestros en medio de la experiencia de producir este curriculum. Asociamos nuestras observaciones durante la pasantía supervisada con una conversación con los estudiantes de pregrado que trabajaron, durante 2019, en una institución escolar específica. En el diálogo con Michel Foucault y Thomas Popkewitz, invertimos en que los procesos alquímicos que transforman las ciencias de referencia en conocimiento escolar también producen, al mismo tiempo, maestros buenos y adecuados (así como no tan buenos y pobres) para enseñarles. Nos dimos cuenta de cuánto se suponía que la noción de autonomía del maestro era central en el proceso de capacitación, en un movimiento que articuló la construcción del currículo en torno al conocimiento, los materiales de enseñanza y las evaluaciones. Aspectos como el uso de actividades prácticas y la creatividad se enunciaron como participantes en la constitución de este buen maestro, capaz de replantear la escuela pública y sus sujetos, y subvertir los modos de regulación y control impuestos por las politicas centralizadas. En 
el proceso formativo, además del conocimiento científico, los enunciados de cunho pedagógico se suponinan bastante significativos en la constitución de un profesional capaz de escapar de la norma, participando en la construcción del curriculim de una manera activa, creativa y autónoma.

Palabras llave: Currículum. Disciplina escolar. Ciencias. Formación de profesores. Alquimia de las disciplinas escolares. Autonomía docente.

Recebido em 25 de fevereiro de 2020

Aceito em 25 de agosto de 2020

Publicado em 24 de setembro de 2020

\section{PRIMEIRAS PALAURAS}

Neste trabalho, investigamos a produção do currículo de Ciências em uma escola municipal do Rio de Janeiro que recebe licenciandos de Ciências Biológicas de uma instituição de ensino superior específica - a Universidade Federal do Rio de Janeiro - para as atividades de estágio supervisionado. ${ }^{3}$ Este estágio é parte da 'Prática de Ensino e Estágio Supervisionado', um componente curricular obrigatório em todos os cursos voltados para a formação inicial de professores da instituição, com carga horária total de 400h. Nele, os futuros professores vivenciam um ano letivo em escolas das redes públicas de ensino, participando das atividades docentes em parceria com professores da educą̧ão básica. Todo o processo é supervisionado, portanto, pela universidade e pela escola, em um movimento no qual as relações entre os envolvidos - professores de Ciências, licenciandos e professores universitários - são constituídas a partir de interações dinâmicas entre ambas as instituições.

Aqui são articuladas as nossas iniciativas de pesquisa, em associação com o ensino e a extensão, em grupos de investigação interessados na História do Currículo, com foco nas reformas educacionais ${ }^{4}$ e nos materiais didáticos. ${ }^{5}$ Interessa-nos, especialmente, olhar para o modo como licenciandos de Ciências Biológicas se constituem professores em meio à experiência de produzir os currículos da educação básica. Para realizar essa tarefa,

3 Ele resulta da articulação dos seguintes projetos de pesquisa: História do Currículo e das Disciplinas: desenvolvimento e uso de uma abordagem discursiva para investigações no ensino e na formação de professores, coordenado pela primeira autora com recursos do CNPq e do CNE/Faperj; Currículo de Ciências e Biologia: um olhar sócio-histórico sobre os materiais didáticos das escolas do Rio de Janeiro, coordenado pela segunda autora com recursos do CNPq e do JCNE/Faperj; Uma alternativa às politicas centralizadas: formar professores e produzir currículos nas escolas, coordenado pela Profa. Dra. Elizabeth Fernandes de Macedo (UERJ) com recursos do CNPq.

4 Estamos nos referindo ao Grupo de Estudos em História do Currículo, que é coordenado pela primeira autora no âmbito do NEC - Laboratório do Núcleo de Estudos de Currículo.

5 Estamos nos referindo ao Grupo de Estudos em Currículos escolares, ensino de Ciências e materiais didáticos, que é coordenado pela segunda autora também no âmbito do NEC - Laboratório do Núcleo de Estudos de Currículo. 
associamos as nossas observações durante o estágio supervisionado com a realização de uma roda de conversa com os licenciandos que atuaram, durante o ano de 2019, em uma instituição escolar municipal específica. Esta foi escolhida por ser uma das escolas parceiras que recebe vários licenciandos e na qual os docentes de Ciências explicitamente se reconhecem como formadores de professores. Não a tomamos, no entanto, como um contexto absolutamente particular no qual se elabora um currículo completamente original. No diálogo com Michel Foucault (1996, 2010 e 2014), entendemos essa produção curricular atravessada por enunciados que estão na ordem do discurso e que podem ser ditos por sujeitos posicionados como professores de Ciências e, simultaneamente, como formadores de professores na área. Assumimos que esse é um interessante contexto no qual os licenciandos se constituem professores.

Tomando como referência a noção de alquimia das disciplinas escolares (POPKEWITZ, 2001, 2010), assumimos que a experiência de produzir o currículo não acontece isolada da experiência de se tornar professor. Diferentemente, investimos na ideia de que os processos alquímicos que transformam as ciências de referência em conhecimentos escolares também produzem, simultaneamente, os professores bons e adequados lassim como os não tão bons e pouco adequados) para ensiná-los. É em meio a esse processo que vimos constituindo padrões e regras para formar professores em cursos de licenciatura no país. No caso das Ciências Biológicas, esses padrões e regras têm envolvido formar professores tanto para o ensino da disciplina escolar Biologia, que se ocupa dos conhecimentos e lógica dessa única ciência de referência, quanto para o ensino de uma disciplina escolar que, de forma integrada, pretende iniciar os estudantes da educação básica nos estudos de cunho científico (FERREIRA; GOMES, 2000; FERREIRA, 2005, 2014). É sobre a formação para essa última - a disciplina escolar Ciências - que versa o presente trabalho, no qual buscamos perceber as articulações que vêm sendo produzidas, no tempo presente, entre a produção dos conhecimentos e dos sujeitos por meio de processos alquímicos (POPKEWITZ, 2001, 2010).

\section{DISCIPLINA ESCOLAR CIÊNCIAS: PRODUZINDO OS SEUS CONHECIMENTOS E SUJEITOS}

Thomas Popkewitz (2001) cunha o conceito de alquimia das disciplinas ${ }^{6}$ escolares para pensar o modo como a escola estadunidense elabora categorias e classificações que 
constituem normas sobre o estudante normal e seu abjeto, o estudante fora da norma. Investigando um programa alternativo para a formação de professores naquele país - o Teach for America -, destinado a recrutar e treinar profissionais de diversas áreas do conhecimento para a atuação em escolas urbanas e rurais, o autor assume uma noção de poder foucaultiana ${ }^{7}$ por meio da qual é possível pensar em como o conhecimento especializado compõe um sistema de pensamento que produz e confina o nosso modo de pensar e agir sobre as (e nas) coisas do mundo. Afinal, de acordo com ele, "o poder desse conhecimento especializado está no fato de não ser apenas conhecimento. As ideias funcionam para modelar a maneira como participamos como indivíduos ativos e responsáveis." (POPKEWITZ, 2001, p. 13).

Nesse movimento teórico, em estreito diálogo com Michel Foucault, o autor enfatiza que, ainda que as perspectivas críticas tenham nos alertado para as relações entre conhecimento e poder, com foco nas desigualdades sociais, a teoria social pós-moderna nos "ofereceu estratégias mais precisas para investigar o conhecimento pedagógico." (POPKEWITZ, 2001, p. 14). Afinal, ela nos possibilitou questionar o que vínhamos assumindo como as verdades do ensino e do modo de pensar sobre os estudantes para além da denúncia, passando a perceber as ações educativas como práticas discursivas que normalizam e diferenciam os sujeitos, confinando-os em espaços por meio dos quais participam e habitam o mundo. É em tal contexto que as disciplinas escolares se inserem, sendo entendidas como o resultado de processos alquímicos que não produzem apenas o conhecimento oficial, mas o tornam parte daquilo que é lógico e atemporal, com efeitos morais sobre os sujeitos da educação. Não é por acaso, portanto, que Thomas Popkewitz (2001, p. 121, grifo do autor) destaca que a alquimia das disciplinas escolares é, simultaneamente, a alquimia dos professores e estudantes, uma vez que, "embora aprendendo conceitos e informações sobre ciências, estudos sociais e matemática, os alunos estão envolvidos em métodos de resolução de problemas para inquirir, organizar e entender como são o mundo e o self." Nesse processo, também os professores vão aprendendo uma ordem moral que os possibilita atuar na profissão e julgar os estudantes.

Essa alquimia envolve, segundo Thomas Popkewitz (2001), uma mistura de práticas educativas que ocorrem em três níveis: $\left(1^{\circ}\right)$ em uma fragmentação dos conhecimentos, que se organizam nas disciplinas escolares de forma supostamente linear, natural e estável, o que possibilita que os professores se concentrem menos na constituição dos currículos e mais nos modos como os estudantes raciocinam; $\left(2^{\circ}\right)$ em uma ênfase em certos recursos textuais, em especial os livros didáticos, que dão materialidade às regras e padrões que normatizam, classificam e diferenciam os estudantes; $\left(3^{\circ}\right)$ em uma relação entre as formas de avaliação e os processos de subjetivação, uma vez que estas vinculam "as normas sociais

\footnotetext{
Nela, o poder não emana de um centro, unicamente identificado com o Estado, e nem age de forma global, homogênea e unicamente repressiva. Isso não significa que o poder não tenha efeitos repressivos; significa que esse é um dos efeitos possiveis, mas não o único. Para Foucault (1996), o poder é parte constituinte das relações sociais, agindo de forma microscópica e produtiva, no sentido de que sempre produz efeitos disciplinadores.
} 
às identidades pessoais através de uma normalização que constitui o desempenho médio, assim como o que constitui o nível ótimo ao qual os alunos devem aspirar." (POPKEWITZ, 2001, p. 114). Nessa mistura, vamos produzindo um mundo supostamente organizado, que pode ser explicado por meio de conhecimentos lógicos e atemporais, ensinados por meio de soluções pedagógicas que regulam o modo como estudantes e professores devem ser classificados, produzindo tanto os sujeitos normais e encaixados nesse mundo quanto os outros, aqueles que fracassam.

É com tal perspectiva que vimos operando para refletir acerca de como, no estágio supervisionado, os futuros professores se constituem na relação com os conhecimentos que vieram produzindo, historicamente, a disciplina escolar Ciências. Estamos nos referindo, aqui, ao componente curricular que tem sido ministrado, desde os anos de 1930 (BRASIL, 1931), no sistema educacional brasileiro, por professores especializados e no nível de ensino que hoje nomeamos segundo segmento do ensino fundamental. Estamos destacando, portanto, que existem diferenças nas verdades que produzimos sobre disciplinas escolares que, apesar de possuírem o mesmo nome, são ministradas por professores com formações diferentes, ancoradas em conhecimentos que, nos processos alquímicos, são atravessados por outros feixes discursivos. Esse é o caso da disciplina escolar Ciências, um componente curricular que, nas séries iniciais do ensino fundamental, tem sido historicamente ministrado por professores generalistas, em estreita articulação entre os outros conhecimentos escolares, enquanto que, nas séries finais desse nível de ensino, ele foi historicamente assumido por professores com formação especializada no que hoje conhecemos como Ciências Biológicas.

Argumentando que as histórias das diferentes disciplinas escolares são atravessadas por feixes discursivos que produzem seus conhecimentos e sujeitos, tomamos aqui a disciplina escolar Ciências que é ministrada nas séries finais do ensino fundamental como um instigante exemplo dessa alquimia que tem, simultaneamente, sustentado e sido sustentada por enunciados de integração curricular, historicamente percebidos como mais fortemente capazes de conectar os currículos aos interesses e demandas dos estudantes. Afinal, ela constitui um exemplo significativo de componente curricular especificamente criado para fins escolares, sem correspondência direta com uma única ciência de referência (MACEDO; LOPES, 2002; FERREIRA, 2005, 2014; GOMES, 2008; GOMES; SELLES; LOPES, 2013). Articulando conhecimentos de diversas áreas científicas ${ }^{8}$ com aqueles advindos da História Natural e, posteriormente, das Ciências Biológicas, podemos dizer que a disciplina escolar Ciências construiu uma história de sucesso na educação brasileira, uma vez que a sua presença nos currículos do ensino fundamental se tornou naturalizada.

Astronomia, Fisica, Geologia e Química, entre outras. 
Tal história veio acompanhando movimentos internacionais que, após a Segunda Guerra, produziram um modo de pensar o mundo e a escolarização que se tornou inseparável da lógica científica. Em nosso país, a disciplina escolar Ciências emergiu oficialmente, nos anos de 1930 (BRASIL, 1931), em meio a enunciados positivistas e pedagógicos que se associaram na assunção de que seria mais adequado e efetivo iniciar os estudantes no estudo das ciências de forma integrada. Para realizar essa tarefa, o ensino experimental foi sendo enunciado como capaz de "aproximar a instituição escolar das ciências de referência, cientificizando conhecimentos escolares que vinham sendo acusados de tradicionais e livrescos, além de atrasados em relação ao que já se havia acumulado no mundo em termos de ciência e tecnologia." (FERREIRA, 2014, p. 191). Além disso, as atividades práticas colocaram professores e estudantes em posições mais ativas, produzindo outras maneiras de pensar os sujeitos adequados (assim como os não adequados) para ensinar e aprender os conhecimentos escolares em ciências. Todo esse movimento pôde reverberar nos materiais didáticos e nas avaliações, forjando um bom professor para a disciplina escolar Ciências que, com autonomia e criatividade, foi instado a participar da produção de atividades de ensino de caráter prático. Podemos dizer que, no tempo presente, tais reverberações permanecem regulando o ensino e a formação de professores na área, em meio a um sistema de pensamento que produz as verdades do mundo a partir de uma racionalidade moderna fortemente ancorada nos conhecimentos científicos. Tais currículos se encontram, portanto, no meio "das lutas mais amplas em torno das definições de quais conhecimentos e racionalidades devem ser considerados válidos socialmente, em um movimento que necessariamente envolve relações de poder." (FERREIRA, 2014, p. 187).

\section{CONSTRUINDO A AUTONOMIA DOCENTE POR MEIO DA ALQUIMIA DAS DISCIPLINAS ESCOLARES: ENTRE CONHECIMENTOS, MATERIAIS DIDÁTICOS E AUALIAÇÕES CURRICULARES}

Tomando como referência os três níveis da alquimia das disciplinas escolares descritos por Thomas Popkewitz (2001), buscamos perceber, por meio de nossas observações durante o estágio supervisionado e, em especial, da realização de uma roda de conversa, como licenciandos do curso de Ciências Biológicas da Universidade Federal do Rio de Janeiro se constituem professores em meio à experiência de produzir os currículos da educação básica. Para realizar essa tarefa, analisamos os relatos de oito licenciandos que estavam completando, em 2019, as atividades de 'Prática de Ensino e Estágio Supervisionado' que tinham sido iniciadas em março do mesmo ano em uma escola pública municipal no Rio de Janeiro. 
Esses relatos foram colhidos em uma roda de conversa realizada no espaço da própria universidade em 21 de novembro de 2019, com a duração aproximada de duas horas. Essa roda de conversa foi por nós conduzida com um duplo propósito: $\left(1^{\circ}\right)$ o de refletir coletivamente sobre a experiência vivenciada, produzindo uma avaliação crítica do estágio; $\left(2^{\circ}\right)$ o de analisar como a experiência do estágio participou da constituição desses sujeitos professores, em um processo que, simultaneamente, é produtor dos currículos da educação básica. Nela, com vistas a entender esses currículos e a formação docente para ensiná-los a partir do olhar dos futuros professores, utilizamos um roteiro que foi por nós organizado em torno de três problematizações: (a) as expectativas prévias desses licenciandos acerca do estágio supervisionado, assim como o grau de adesão ou correspondência das mesmas com a experiência até então vivenciada; (b) aspectos relacionados ao currículo de Ciências - o planejamento e a realização das aulas, a seleção e a organização dos conhecimentos a serem ensinados, a produção e uso de materiais didáticos, a interface com orientações e documentos oficiais, as formas de avaliação; (c) as críticas dos licenciandos a esse currículo. Tais problematizações orientaram a roda de conversa em três momentos, possibilitando a emergência de discursos sobre a produção do currículo da disciplina escolar Ciências e sobre o modo como esses licenciandos vieram se constituindo professores nesse processo.

Com a autorização dos licenciandos, a roda de conversa foi gravada em áudio e posteriormente transcrita, tornando-se parte do nosso arquivo de pesquisa, ensino e extensão. Essa transcrição foi analisada "na sua materialidade pura e simples de coisas ditas em determinado tempo e lugar" (FISCHER, 2007, p. 43-44), em meio a leituras e releituras no âmbito das quais emergiram práticas sociais que constituem a disciplina escolar Ciências e, simultaneamente, formam os sujeitos envolvidos no estágio supervisionado. Nessa análise, inspiradas em Michel Foucault (2010, p. 157), não estivemos interessadas em delimitar "os pensamentos, as representações, as imagens, os temas, as obsessões que se ocultam ou se manifestam nos discursos, mas os próprios discursos, enquanto práticas que obedecem a regras." A intenção foi, portanto, a de investigar os próprios discursos, sem relacionálos a uma suposta origem a partir do qual teriam surgido e muito menos a uma espécie de propriedade desses sujeitos licenciandos que puderam falar. Afinal, são as regras das práticas discursivas "que atravessam obras individuais, às vezes as comandam inteiramente e as dominam sem que nada lhes escape; mas às vezes, também, só lhes regem uma parte. A instância do sujeito criador, enquanto razão de ser de uma obra e princípio de sua unidade, lhe é estranha." (FOUCAULT, 2010, p. 158).

No processo de análise, percebemos o quanto a noção de autonomia docente foi assumida como central no processo formativo, em um movimento que articulou a construção curricular em torno dos conhecimentos, dos materiais didáticos e das avaliações. Em estreito diálogo com os professores da disciplina escolar Ciências, os licenciandos em formação descreveram uma série de ações realizadas durante o estágio supervisionado - 
das observações às regências de aula, da seleção dos fragmentos de conhecimentos aos planejamentos, do uso dos textos oficiais à produção de materiais didáticos -, significando-as em meio ao processo de se tornarem bons profissionais, capazes de agir com autonomia no cotidiano de uma escola pública no cenário atual.

Isso significa entender que, no processo formativo, esses licenciandos foram incorporando a ideia de que um bom professor é aquele que age com autonomia na produção do currículo da disciplina escolar Ciências. Um primeiro aspecto relativo a essa autonomia referiu-se ao modo como os conhecimentos da formação e do ensino se articulam nessa produção curricular, em um movimento no qual os discursos pedagógicos orientam as decisões em torno de quais fragmentos de conhecimentos deveriam estar no currículo. Desses discursos pedagógicos, emergem enunciados que reafirmam, por exemplo, o quanto as experiências em disciplinas da formação inicial provocaram mudanças nos modos de pensar essa questão. Foi o caso, por exemplo, de uma "disciplina (que) falava muito sobre a questão do CTSA, que está relacionado com Ciência, Tecnologia, Sociedade e Ambiente, e isso, esse tipo de coisa ficou muito na minha cabeça, e eu fiquei pensando de como levar isso para a escola." (L1) (informação verbal). Para essa mesma licencianda, um dos aspectos que mais chamou a sua atenção ao longo do processo formativo foi a possibilidade de transformar o conhecimento acadêmico aprendido em currículo, uma vez que, com essa "liberdade que os professores dão para a gente bolar atividades e planejar aulas, a gente consegue fazer o recorte meio que da nossa maneira, valorizando determinados conhecimentos que são produzidos aqui [na universidade], até conhecimentos novos que os alunos não teriam fácil acesso." (L1) (informação verbal). Essa questão emergiu em enunciados que abordam a seleção dos conhecimentos a serem ensinados, como no seguinte exemplo sobre as decisões em torno da abordagem da diversidade animal:

\footnotetext{
E assim, a gente valorizaria muito mais los animaisl, porque o sétimo ano é mais pra ser uma explanação da diversidade. E porque falar da diversidade nesse âmbito? Afinal de contas, a maioria deles [dos estudantes] não vai ser biólogo, não interessa pra eles saber as classificações dos grandes grupos. 0 interessante pra eles, o que eu achei, que a mensagem que a gente queria passar pra eles, é fazer de fato eles se sentirem identificados com os animais, conhecerem os animais para ter empatia pelos animais, para ter empatia pela natureza, para entender porque é importante preservar alguma coisa, ainda que ela esteja muito distante da sua. Então foi, foi o que eu tentei passar para eles na minha aula. (L2) (informação verbal).
}

Tais experiências em disciplinas da formação inicial foram também significativas na construção de um outro olhar sobre as escolas públicas, seus estudantes e professores, uma vez que, até o ingresso no curso de graduação, estas eram vistas como inferiores na relação com um ideal de escola privada. Para um dos licenciandos, por exemplo, foi "na 
Licenciatura, conversando sobre a docência, conversando sobre didática, conversando sobre o papel do professor e o papel do aluno e como isso acontece na prática", que ele começou a descontruir uma imagem estereotipada das escolas municipais, ainda que tenha sido durante o estágio supervisionado que essa desconstrução ocorreu de forma mais efetiva:

[..] ainda assim, fica um resquício na sua cabeça até você de fato estar lá dentro e entender como é que funciona essa prática e como é que funciona essa relação. Então, eu posso dizer que realmente a Prática [de Ensinol, ela mudou muito a minha cabeça, mudou muito a maneira como eu pensava a escola, como eu pensava a relação entre professor e aluno (L3) (informação verball.

Uma sólida formação acadêmica foi vista, portanto, como um elemento importante na constituição da autonomia docente, ainda que não tenha sido percebida como suficiente nesse processo. Partindo dela, caberia, então, a um bom professor as decisões em torno de quais conhecimentos selecionar e recortar, de acordo com características que extrapolam a lógica da organização científica e que estariam mais centralmente ancoradas em enunciados de cunho pedagógico, uma vez que relacionados à realidade dos estudantes e ao cotidiano das salas de aula do ensino fundamental. Afinal, "tem coisas que a gente só aprende mesmo fazendo, mas ao mesmo tempo a gente tem uma bagagem acadêmica muito forte. Então, a gente chega com um vasto conhecimento, mas tem que fazer aquele recorte para dar uma determinada aula." (L1) (informação verbal). Observe como esses critérios de seleção e recorte dos conhecimentos foram enunciados na construção de um currículo que, para os licenciandos, fugiu à norma:

É, e tem outros conteúdos que o professor acha interessante os alunos saberem [...] Que para aquele aluno, para aquela turma, aquele conteúdo faz mais sentido, entendeu... Que vai trazer mais a realidade do aluno, só que ele não tem tempo pra dar, porque ele tem que dar aqueles conteúdos de uma maneira bem robótica mesmo, sabe? [...] E aí eu fui fazendo a minha aula em cima disso né, botei muito, que nem o [outro licenciando] fez também, botei muita fauna nativa, enfim... (L3).

Curiosidades também, né? Coisas que a gente acha que podem agregar na vida deles. (L4).

Que foge um pouco, então a gente, acha que não existe, assim, [...] existe um engessamento por causa disso, mas... É, há possibilidades de pegar elementos que tão fora [do currículo], né? Eu acho que é nessas possibilidades que a gente realmente consegue construir essa autonomia do professor. (L3) linformações verbais). 
Na alquimia da disciplina escolar Ciências, realidade e cotidiano foram significados, portanto, por conhecimentos sobre a fauna nativa do Rio de Janeiro, assim como aqueles que respondem às curiosidades dos alunos acerca das temáticas científicas. A noção de realidade também foi preenchida pelos licenciandos por um entendimento de que existe uma diversidade de modos de uma escola pública se constituir na sociedade brasileira e, no caso desse estudo, no município do Rio de Janeiro; afinal, como uma das licenciandas destaca, se referindo à sua experiência escolar anterior ao estágio supervisionado, que foi construida no ensino privado: "eu queria tentar ver outras realidades, eu queria tentar ver uma realidade diferente da minha, por isso eu tentei fazer essa escolha." (L5) (informação verbal). Nessa nova realidade, que associou a instituição e seus sujeitos, os fragmentos de conhecimentos que passaram a constituir o currículo foram sendo também atravessados pelas expectativas dos licenciandos em formação inicial, voltadas tanto para o planejamento das aulas - o que inclui o uso das metodologias mais adequadas - quanto para o aprendizado de qualidades percebidas como intrínsecas ao bom professor, como é o caso do domínio de turma:

\begin{abstract}
Inclusive no meu diário [de campol estava escrito isso: 'acho que eu não vou ter domínio de turma, isso vai ser horrivel' (risos). E com essa experiência na Prática de Ensino, eu tive que aprender, com diferentes professores, a saber como eles lidam com a turma, aprender também um pouco essa experiência de como ter domínio de turma, também, eu aprendi com cada um [dos professores regentes um] pouco de como eles funcionam. (L5) (informação verbal).
\end{abstract}

No que se refere ao planejamento das aulas da disciplina escolar Ciências, os licenciandos destacaram o quanto que as qualidades de um bom professor envolvem a constituição de uma autonomia na escolha e uso das metodologias mais adequadas. Isso foi significativo durante o estágio supervisionado, espaço formativo onde eles

puderam produzir aulas práticas, Feira de Ciências, aulas teóricas também, assim, coisas além do pilot no quadro, não é... Todas essas coisas que fogem um pouco do que a gente considera padrão. [Mas] elas não seriam possiveis de estarem presentes naquele colégio se os licenciandos, enfim, tem PIBID também, se não tivessem todos aqueles estagiários lá dentro. (L3) (informação verbal).

Afinal, eles esperavam "uma passividade muito maior dos estagiários com relação ao currículo, com relação à atuação nas aulas, em relação ao planejamento da disciplina de uma maneira, assim, mais direta." (L3) (informação verbal). Essa oportunidade de ser ativo na formulação e implementação do currículo foi assumida, então, como parte do processo de constituição da autonomia docente, em um movimento que produziu, simultaneamente, a 
passividade como uma das características do mau professor. Isso se referiu, por exemplo, a "conhecer, [...] ter uma postura diferente, uma abordagem diferente, [...] ter na sua cabeça de que o caminho vai ser outro porque você conhece (L2) (informação verbal).

Em tal planejamento, as atividades práticas ganharam destaque, reafirmando 0 papel das mesmas na constituição dos currículos e professores da disciplina escolar Ciências. Elas participaram da constituição desses licenciandos como bons professores em variados aspectos. Em primeiro lugar, essas atividades foram percebidas como mais prazerosas para todos os envolvidos, evitando que esse profissional caia em uma rotina na qual perca a sua autonomia. Segundo um dos licenciandos, "quando lele] dava uma prática legal, não só os alunos se divertiam, [...] [ele se] divertia também de estar dando uma aula diferente;" (L4) (informação verbal). De acordo com outro, o prazer estava em dar uma aula e perceber o interesse dos alunos sobre o tema, o que se evidenciava em conversas ou debates sobre o mesmo (L3) (informação verbal). Em segundo lugar, elas foram assumidas como facilitadoras da aprendizagem. Observe o modo como, na escola campo de estágio, professores e licenciandos lidavam com essa questão:

\footnotetext{
Eles los professores] percebem, por exemplo, que tem [um] aluno determinado, [ou um] assunto que o aluno está tendo dificuldade... Foi o caso do sistema ABO. Os alunos não estavam conseguindo entender, então, ai foi [lançada] a questão: 'gente, vamos ter que bolar uma atividade prática para tentar ajudar esses alunos'. Então tem muito isso também, da demanda dos alunos, das dificuldades. Então, assim, se o método tradicional não está dando certo, o que a gente pode fazer pra agregar. (L1).
}

Então por mais que tenha aquela coisa engessada, que você tenha que passar aquele conteúdo, eu tenho que passar, mas eu tenho que passar esse conteúdo de uma outra forma, com uma outra visão que dá pra passar, que o aluno consegue aprender, e que eu tenho o meu retorno, eu fico feliz, o meu aluno fica feliz. Tipo, é o que a outra licencianda sempre falava: eu vivo nessa Escola, eu tenho um monte de estresse, mas eu vivo feliz, porque só de ver que os alunos estão aprendendo, eu fico feliz. Então, é esse retorno que ela acha que é um retorno interessante pra gente como professor. Tipo, eu estou passando conteúdo, eu vou fazer um milhão de atividades, eu vou fazer um milhão de práticas, mas o que que eu quero no final? Eu quero que meu aluno aprenda, quero que ele saia daqui sabendo - que eu quis passar pra ele, seja a forma que eu, qualquer forma que eu tenha passado. (L6) (informações verbais).

Além de prazerosas e de facilitadoras da aprendizagem, as atividades práticas foram enunciadas como capazes de participar da constituição da autonomia docente, uma vez que possibilitam um significativo deslocamento da lógica universitária para a lógica escolar. Segundo uma das licenciandas, isso foi como "sair da caixinha", uma vez que, no processo formativo, após quatro ou cinco anos dentro de uma universidade, "é para a gente passar 
para o aluno o que a gente aprendeu [...] de uma outra forma, com uma outra visão. Então esse sair da caixinha é justamente fazer o que a gente estudou [...] durante cinco anos." (L6) (informação verbal).

Também a criatividade foi enunciada como participando da constituição desse bom professor que, com autonomia na produção do currículo, foi capaz de elaborar materiais alternativos e atividades práticas para o ensino de conhecimentos supostamente tradicionais. Esse foi o caso, por exemplo, de uma das professoras da escola que, ao ensinar sobre os átomos, primeiro "ela fez aquela aula totalmente no quadro, falou de tudo, deu todas as definições. Depois ela pegou papel, bolinhas de papel colorido, e propôs: vamos fazer, vamos botar o átomo central, vamos colocar os elétrons em volta, vamos botar as bolinhas representando cada coisa." (L7) (informação verbal). Essa foi uma experiência formativa bastante significativa para uma das licenciandas, uma vez que percebeu o quanto os estudantes "adoraram aquilo, e foi uma forma de [...] falar [sobre] aquilo que está programado [...], mas [...] de uma forma lúdica, de uma forma representativa pra eles. Eu acho isso muito, muito superação dos professores ali." (L7) (informação verbal). Em direção semelhante, outra licencianda destacou a criatividade de outro professor da escola, que em "todo bimestre ele fazia coisas diferentes, ele trabalhava com materiais diferentes, ele botava propostas diferentes." (L1) (informação verbal). Como exemplo dessa questão, ela citou o uso de um "aplicativo pago, que ele pagou do bolso dele, que mostra as estruturas do corpo humano, então quando ele vai dar uma aula, por exemplo, de sistema cardiovascular, ele projeta do celular dele, e aí ele consegue mostrar como é que é o percurso [do sangue] de uma forma diferente." (L1) (informação verbal).

Dois outros aspectos relacionados ao modo como esses licenciandos, por meio da alquimia das disciplinas escolares, foram se constituindo professores e assumindo a autonomia como um valor, dizem respeito à relação entre as decisões curriculares cotidianas e as orientações oficiais expressas em materiais didáticos e avaliações. Vale ressaltar que a Secretaria Municipal de Educação do Rio de Janeiro vem adotando uma política curricular que tem por base a produção e a distribuição de materiais didáticos (nomeados de Cadernos Pedagógicos) a partir dos quais têm sido elaboradas avaliações aplicadas a todos os estudantes dessa rede de ensino. Nesse cenário, há ainda a presença de livros didáticos enviados às escolas pelo Ministério da Educação, por conta do Programa Nacional do Livro Didático. Como explicita Thomas Popkewitz (2001), tanto os materiais didáticos quanto as avaliações são parte importante dos processos alquímicos que constituem os conhecimentos e sujeitos da educação. No caso da disciplina escolar Ciências, com fortes tradições em ambos os aspectos, os licenciandos puderam perceber os efeitos dessa alquimia na constituição dos modos de ser professor. 
Essa dinâmica, que se estabelece articulando os modos de uso dos materiais didáticos - em especial, dos Cadernos Pedagógicos - à aplicação das avaliações oficiais, foi explicitamente reconhecida pelos licenciandos quando afirmaram a existência de uma forte regulação do currículo da disciplina escolar. No que se refere aos Cadernos Pedagógicos, um dos licenciandos destacou, por exemplo, "que a primeira coisa que eles los professores] pensavam sempre que iam entrar em um conteúdo era como é que está na apostila. A primeira coisa que eles falavam para a gente lera]: 'como é que está na apostila? Vamos olhar a apostila.' Aí eles davam a apostila para a gente." (L4) (informação verbal). Essa significativa associação entre as decisões curriculares e os textos oficiais - os quais, de acordo com Thomas Popkewitz (2001), produzem e legitimam os conhecimentos escolares como objetos lógicos e atemporais - foi continuamente analisada pelos licenciandos durante o estágio supervisionado, desafiando a autonomia docente como o principal valor a ser adquirido pelos bons professores. Aliada às avaliações oficiais periódicas, essa autonomia foi sendo tensionada ao longo de todo o processo, uma vez que, de acordo com outra licencianda, "tudo [no currículo] é em volta dessa prova." (L5) (informação verbal). Isso foi enunciado, inclusive, nos momentos de explícita preocupação dos professores com as mudanças curriculares propostas pela Base Nacional Comum Curricular (BRASIL, 2018). Nesse contexto, "os professores vão ser obrigados sim a entrarem nessa mudança, porque a prova do município, ela vai vir de acordo com essa mudança, então a apostila vai vir de acordo com essa mudança. Então eles vão ter que seguir aquilo porque vai ter prova." (L7) (informação verbal). Em tal direção, outra licencianda deu um exemplo de como a avaliação interferiu de modo ambivalente na seleção e organização dos conhecimentos da sua regência, uma vez que explicitou a pouca importância que o currículo oficial dá para o tema anfíbios, mas oportunizou que ela fizesse um planejamento mais autônomo, uma vez que menos regulado pelos textos oficiais:

\footnotetext{
Por exemplo, a professora foi olhar a prova, ela sempre dá uma olhada na prova da SME... Olhar as questões para poder passar para eles los estudantes] tipo uma revisão, para estudar, para poder fazer a prova. Aí ela olhou pra mim para ver [...] o que caía de anfibios, para eu poder passar [... na regência. Mas não cai nada de anfibios. Na prova não cai nada, nada, nada. Ela falou: Então a tua aula vai ser livre, dá o que você quiser, porque nela não cai anfibios, a SME não pede, nunca. Eu falei: Poxa. (L5) (informação verbal).
}

Entretanto, essa preocupação com uma necessidade de obediência aos textos e avaliações oficiais foi também tensionada por movimentos na direção de uma construção de alternativas para o enfrentamento da questão. Assim, em meio a diálogos e debates com os professores, os licenciandos foram se envolvendo em questionamentos acerca do que le de como) utilizar os Cadernos Pedagógicos na construção do currículo da disciplina escolar: 
E a apostila eu sinto que ela oscilava muito entre... Ela ia de extremos, de péssimo a bom, não diria ótimo, bom. Por exemplo, a Botânica, que foi uma parte da apostila que eu analisei bastante, leul achei excelente. Para o sétimo ano estava ótimo. Eles, inclusive, destacavam locais aqui no Rio de Janeiro, eles falavam do Parque do Itatiaia, Jardim Botânico e faziam meio que um passeio nesses lugares para usar como exemplo. Então, acho que é um exemplo ótimo eles los estudantes] poderem ir até o Jardim Botânico, conhecer aquele lugar. Eu acho que mexe um pouquinho na questão da vivência deles, às vezes a gente fala da Botânica, fala daqueles ciclos de vida que parecem uma coisa alienígena... Assim, são células que eles não vêem, elas ficam muito abstratas. [...] [Já] a Zoologia, por exemplo, pegava répteis em uma página, anfibios em uma página, aves em uma página, mamiferos em duas páginas e acabou. (L4) (informação verbal).

Nesse contexto, no qual o exercício da autonomia docente foi enunciado como o aprendizado mais significativo da formação no estágio supervisionado, os licenciandos foram aprendendo a escapar dos controles impostos pelos Cadernos Pedagógicos e avaliações externas. Tal movimento se deu por meio de uma análise constante dessas superfícies textuais, com vistas a entender os recortes, ênfases e seleções daquilo que veio contando como currículo oficial. Nele, os licenciandos foram aprendendo a tomar as melhores decisões acerca do que (e de como) ensinar, assumindo que a constituição de um professor autônomo passa pela capacidade de decisão sobre o que é (e o que não é) um bom ensino de Ciências. Sobre essa questão, é elucidativa a fala de um dos licenciandos participante da roda de conversa:

Sabe, lvocêl não precisa ir tanto, não só na característica científica, técnica da coisa, mas trabalhar um pouquinho o que eles vêem. [Por exemplo,] a imagem que tinha [na apostila] era a de um pavão. Quantos alunos ali [já] viram um pavão? Ainda mais um pavão assim, em época reprodutiva, que ele abre o negócio, grandão assim. Por que não coloca um passarinho que eles vêem? Por que eles não falam um pouquinho da fauna brasileira, lo que] eu acho super importante. Uma coisa que eu quis trazer na regência, leu] colocava os animais com os nomes e falava: olha, esse animal é brasileiro. Eu acho super importante eles conhecerem isso, e usar isso de exemplo e, claro, tem que explorar um pouco mais, eu acho que a apostila em si está muito limitada. (L4) (informação verbal).

Foi em meio à referida tensão entre as formas de controle do currículo e do trabalho docente impostas por uma política municipal centralizada - da qual fazem parte os Cadernos Pedagógicos e as avaliações - e a criação de alternativas no enfrentamento dessa questão que os licenciandos perceberam a inserção dos livros didáticos do Programa Nacional do Livro Didático. Se, por um lado, esse programa em caráter nacional foi visto como bastante centralizador, uma vez que foi explicitamente associado às mudanças curriculares estabelecidas pela Base Nacional Comum Curricular (BRASIL, 2018), por outro lado, os livros didáticos recebidos na escola serviram como referência tanto para questionar a qualidade 
dos textos oficiais do município, em particular a dos Cadernos Pedagógicos, quanto para balizar as escolhas curriculares em meio aos conhecimentos acadêmicos da área:

\begin{abstract}
Então, eu usei muito texto acadêmico, porque é o que eu estou acostumada a fazer. Se eu estou procurando uma informação que é segura, a primeira coisa que eu faço é olhar em textos lacadêmicos]. Mas o que eu pensei também [foi quel, já que eu estava tendo dificuldades em fazer a transposição, também olhei alguns livros didáticos da minha mãe, porque a minha mãe é professora, então ela tem muitos livros didáticos. (L2) (informação verbal).
\end{abstract}

Os livros didáticos serviram, portanto, "para estudar, como fonte de planejamento" (L3) (informação verbal), atuando como dispositivos que participaram, no caso dessa investigação, dos processos que regulam e subvertem as escolhas curriculares centralizadas. Eles participaram, portanto, da construção desse bom professor, que foi aprendendo, ao longo do estágio supervisionado, como agir com autonomia em meio aos Cadernos Pedagógicos, às avaliações centralizadas e aos livros didáticos articulados à Base Nacional Comum Curricular (BRASIL, 2018). Essa autonomia foi sendo enunciada, por exemplo, quando uma das professoras da escola "propôs algumas atividades daquelas práticas de livros [didáticos]" (L3) (informação verbal). Na ocasião, um dos licenciandos pôde explicitar o caminho que foi percorrido na direção de uma maior autonomia docente, assumindo que:

\footnotetext{
[...] com o tempo a gente foi desenvolvendo isso, eu sinto que esse, esse nível de autonomia que a outra licencianda se refere quando ela la professoral fala para a gente pensar em atividade, para a gente planejar, para chegar [...] e falar olha, pensei nisso aqui... É aplicável? Quando é que eu posso fazer? Isso foi sendo desenvolvido ao longo da Prática de Ensino. (L3) (informação verbal).
}

Outra licencianda ratifica essa questão ao enunciar a autonomia docente como uma característica adquirida gradualmente na formação inicial, em meio a inseguranças relacionadas ao ingresso na profissão. De acordo com ela, estas foram enfrentadas coletivamente, uma vez que boa parte das atividades foram produzidas em grupo, "então de certa forma isso divide, isso dilui la responsabilidade] entre o grupo, então você não se sente sozinho. Porque quando você vai fazer uma atividade sozinho tem um peso maior, não é?" (L1) (informação verbal). Refletindo como os modos de organização dos tempos e espaços escolares, assumidamente percebidos como diferentes dos tempos e espaços acadêmicos, essa gradual transferência de responsabilidade no planejamento e execução de determinadas atividades de ensino foi vivenciada em meio a fortes emoções, como aqui destacado: "então, a autonomia me assustou duas vezes, uma quando eu precisei fazer uma atividade sozinha, [...] uma prática inteira sozinha, foi a prática de órgãos dos sentidos [...] e o professor queria 
tipo assim de domingo para segunda." (L5) (informação verbal). Nesse processo, como já explicitado, a autonomia docente foi se constituindo como a principal característica de um bom professor de Ciências, que deveria estar preparado para produzir um currículo antenado com as tradições disciplinares e, ao mesmo tempo, escapar das formas de controle impostas pelas políticas centralizadas nos níveis municipal e nacional.

\title{
4 CONSIDERAÇÕES FINAIS
}

\begin{abstract}
Eu acho que a gente tinha dois tipos de autonomia na escola, [uma] autonomia que os professores já vinham com uma ideia, 'ah, eu quero fazer uma prática do Reino Monera', por exemplo, ai nós tínhamos que desenvolver isso. E aí tinha loutra] autonomia tipo assim 'ah, professora eu pensei nesse assunto aqui, eu queria dar isso, eu fiz o planejamento eu tenho uma aula aquii' (L7) (informação verbal).
\end{abstract}

Neste estudo, investigando a produção do currículo da disciplina escolar Ciências em uma escola municipal em meio às atividades de estágio supervisionado, a autonomia docente emergiu como a principal característica a ser adquirida por um bom professor. No diálogo com Thomas Popkewitz (2001, 2010) e interessadas no modo como os licenciandos se constituem professores em meio à experiência de produzir esse currículo, evidenciamos como os conhecimentos, os materiais didáticos oficiais e as avaliações centralizadas participaram de uma alquimia que transforma aquilo que ensinamos e aprendemos na escola em objetos lógicos e atemporais. Nesse processo, tornar-se um bom profissional foi sendo significado como atuar com relativa autonomia nas decisões curriculares em meio às formas de controle exercidas pelas políticas. Tal atuação envolveu, por exemplo, um aprendizado na seleção e uso de atividades de ensino tradicionais na área - tais como as aulas práticas e a realização de uma Feira de Ciências -, tomando como referência a integração curricular, uma característica da disciplina escolar fortemente relacionada aos interesses e demandas dos estudantes.

A noção de autonomia docente também possibilitou aos licenciandos a produção de outros modos de significar a escola pública e seus sujeitos, deslocando-os de experiências escolares anteriores nas quais a escola privada era o modelo a ser seguido. Nesse contexto, realidade e cotidiano foram ressignificados, produzindo um currículo centralmente atravessado pelas expectativas desses licenciandos quanto ao aprendizado de qualidades percebidas como intrínsecas ao bom professor para a atuação nesse novo cenário, o da escola pública. No processo formativo, uma sólida formação acadêmica foi enunciada como um elemento de grande valor na constituição dessa autonomia, ainda que não suficiente. Os enunciados de cunho pedagógico foram assumidos como bastante significativos na constituição de um 
profissional capaz de fugir à norma na construção do currículo. Esse bom professor para a disciplina escolar Ciências foi se constituindo, então, no estágio supervisionado, significando a docência na educação básica como ativa, criativa e autônoma. Nessa produção das verdades do ensino e da formação de professores, foram também construídos significados acerca dos maus professores da área, em um movimento ambivalente por meio do qual os sujeitos da educação vão sendo classificados, avaliados e diferenciados.

\section{REFERÊNCIAS}

BRASIL. Base Nacional Comum Curricular. Brasilia, DF: MEC, 2018.

BRASIL. Decreto 19.890, de 18 de abril de 1931. Dispõe sobre a organização do ensino secundário. Diário Oficial, Rio de Janeiro, 1 maio 1931.

FERREIRA, M. S. A história da disciplina escolar Ciências no Colégio Pedro II (1960-1980). 2005. Tese (Doutorado) - Universidade Federal do Rio de Janeiro, Rio de Janeiro, 2005.

FERREIRA, M. S. Currículo e cultura: diálogos com as disciplinas escolares Ciências e Biologia. In: MORElRA, A. F.; CANDAU, V. M. (org.). Currículos, disciplinas escolares e culturas. Petrópolis, RJ: Vozes, 2014.

FERREIRA, M. S.; GOMES, M. M. Emergência da disciplina escolar Ciências nos currículos oficiais brasileiros (1931-1971). In: ENCONTRO PERSPECTIVAS DO ENSINO DE BIOLOGIA, 7., 2000, São Paulo. Anais [...] São Paulo: FEUSP, 2000. p. 704-708.

FISCHER, R. M. B. A paixão de trabalhar com Foucault. In: VEIGA-NETO, A. et al. Caminhos Investigativos I: novos olhares na pesquisa em educação. Rio de Janeiro: Lamparina, 2007.

FOUCAULT, M. A arqueologia do saber. 7. ed. Rio de Janeiro: Forense Universitária, 2010.

FOUCAULT, M. A ordem do discurso. São Paulo: Edições Loyola, 2014.

FOUCAULT, M. Microfisica do poder. 12. ed. Rio de Janeiro: Edições Graal, 1996.

GOMES, M. M. Conhecimentos ecológicos em livros didáticos de Ciências: aspectos sócio-históricos de sua constituição. Tese (Doutorado) - Universidade Federal Fluminense, Rio de Janeiro, 2008.

GOMES, M. M.; SELLES, S. E.; LOPES, A. C. Currículo de ciências: estabilidade e mudança em livros didáticos. Educação e Pesquisa, v. 39, p. 477-492, 2013.

MACEDO, E.; LOPES, A. C. A estabilidade do currículo disciplinar: o caso das ciências. In: LOPES, A. C.; MACEDO, E. (org.). Disciplinas e integração curricular: histórias e políticas. Rio de Janeiro: DP\&A, 2002. p. 73-94. 
POPKEWITZ, T. S. Lutando em defesa da alma. A política do ensino e a construção do professor. Porto Alegre: Artmed Editora, 2001.

POPKEWITZ, T. S. The limits of teacher education reforms: school subjects, alchemies, and an alternative possibility. Journal of Teacher Education, v. 61, n. 5, p. 413-421, Nov. 2010.

Endereço para correspondência: Avenida Pasteur, 250, Palácio Universitário, $2^{\circ}$ andar, Campus da Praia Vermelha, Rio de Janeiro, Brasil; marciaserraferreira@gmail.com 


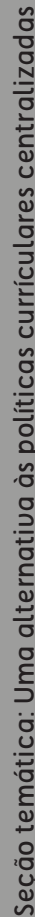

